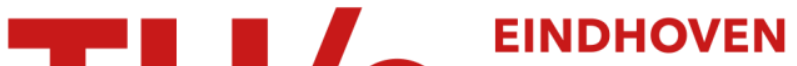 \\ UNIVERSITY OF \\ TECHNOLOGY
}

\section{Prediction model for the diurnal behavior of the tropospheric scintillation variance}

\section{Citation for published version (APA):}

Tervonen, J. K., Kamp, van de, M. M. J. L., \& Salonen, E. T. (1998). Prediction model for the diurnal behavior of the tropospheric scintillation variance. IEEE Transactions on Antennas and Propagation, 46(9), 1372-1378.

https://doi.org/10.1109/8.719982

DOI:

10.1109/8.719982

Document status and date:

Published: 01/01/1998

\section{Document Version:}

Publisher's PDF, also known as Version of Record (includes final page, issue and volume numbers)

\section{Please check the document version of this publication:}

- A submitted manuscript is the version of the article upon submission and before peer-review. There can be important differences between the submitted version and the official published version of record. People interested in the research are advised to contact the author for the final version of the publication, or visit the $\mathrm{DOI}$ to the publisher's website.

- The final author version and the galley proof are versions of the publication after peer review.

- The final published version features the final layout of the paper including the volume, issue and page numbers.

Link to publication

\section{General rights}

Copyright and moral rights for the publications made accessible in the public portal are retained by the authors and/or other copyright owners and it is a condition of accessing publications that users recognise and abide by the legal requirements associated with these rights.

- Users may download and print one copy of any publication from the public portal for the purpose of private study or research.

- You may not further distribute the material or use it for any profit-making activity or commercial gain

- You may freely distribute the URL identifying the publication in the public portal.

If the publication is distributed under the terms of Article 25fa of the Dutch Copyright Act, indicated by the "Taverne" license above, please follow below link for the End User Agreement:

www.tue.nl/taverne

Take down policy

If you believe that this document breaches copyright please contact us at:

openaccess@tue.nl

providing details and we will investigate your claim. 


\title{
Prediction Model for the Diurnal Behavior of the Tropospheric Scintillation Variance
}

\author{
Jouni K. Tervonen, Max M. J. L. van de Kamp, and Erkki T. Salonen
}

\begin{abstract}
Tropospheric scintillation is caused by variations of refractive index due to turbulence. The only meteorological input parameter for two common current scintillation models by Karasawa $e t$ al. and by ITU-R is the monthly average of wet part of refractivity $N_{\text {wet }}$ at ground level, which is not directly associated with turbulence. The diurnal correlation between $N_{\text {wet }}$ and scintillation variance is very weak. Because clouds and cloud formation are closely associated with the turbulence, quantitative cloud parameters were looked for. Cloud type information based on edited synoptic cloud reports are available from common database of CDIAC and NCAR. Both diurnal and seasonal variations between scintillation variance and average amount of Cumulus type clouds are well correlated. Using this cloud information together with $N_{\text {wet }}$, a new method for tropospheric scintillation variance predicting also diurnal variations is introduced. This model is derived and tested using scintillation measurements at four sites in different climates in Finland, United Kingdom, Japan, and Texas
\end{abstract}

Index Terms-Cumulus clouds, low-fade margin, meteorology, propagation, radio-wave propagation, satellite communication, tropospheric turbulence.

\section{INTRODUCTION}

$\mathbf{S}$ MALL-SCALE turbulent fluctuations of the refractive index along a propagation path cause amplitude, phase, and angle of arrival variations known as scintillation. Clear seasonal and diurnal variations of scintillation have been observed and reported in literature [1]-[8]. Because many services are related to the hour of the day, the diurnal behavior of fades is an important factor in planning satellite communication systems. Tropospheric scintillation should be considered together with the attenuation phenomena of precipitation, clouds, and atmospheric gases in planning Earth-space links for low-fade margin communication systems [9]. Scintillation can become a significant impairment particularly at low elevation angles.

Scintillation prediction models have been described by Karasawa, Yamada, and Allnutt [10] and ITU-R [11]. Both of these models use the wet part of refractivity $N_{\text {wet }}$, a function of relative humidity and temperature measured at

Manuscript received April 17, 1997; revised November 26, 1997. This work was supported in part under ESA/ESTEC Contract 10827/94/NL/NB(SC).

J. K. Tervonen is with the Helsinki University of Technology, Radio Laboratory, FIN-02015 HUT, Finland.

M. M. J. L. van de Kamp was with Helsinki University of Technology. He is now with the Eindhoven University of Technology, 5600 MB Eindhoven, The Netherlands.

E. T. Salonen was with Helsinki University of Technology. He is now with the University of Oulu, Telecommunication Laboratory, FIN-90571 Oulu, Finland.

Publisher Item Identifier S 0018-926X(98)06877-X. ground level averaged at least over a month, as an input parameter. Scintillation is generally related with the occurrence of clouds, especially Cumulus-type clouds. We were interested in finding out a method to include cloud information in the prediction model. Clouds and cloud formation are in fact more closely associated with atmospheric turbulence (the cause of scintillation) than the wet part of refractivity $N_{\text {wet }}$ at ground level.

\section{THEORY}

Both from theory and experiments, it is known that on a time scale up to several minutes signal level fluctuations due to turbulence, in decibels, show a Gaussian distribution around the mean signal level. This is why they can be completely characterized by the variance $\sigma^{2}$. The variance over one minute is commonly used for this purpose. Instead of the variance one can also use the standard deviation $\sigma=\sqrt{\sigma^{2}}$, often called the "scintillation intensity." On a long-term basis, correlation between the scintillation variance/intensity and meteorological parameters is generally observed.

In the prediction models presented by Karasawa, Yamada, and Allnutt [10] and ITU-R [11], the long-term scintillation variance is expressed as related to $N_{\text {wet }}$, which is a function of relative humidity $U(\%)$ and temperature $t\left({ }^{\circ} \mathrm{C}\right)$, measured at ground level as

$$
N_{\text {wet }}=3730 \frac{U e_{s}}{(t+273)^{2}}(\mathrm{ppm})
$$

where $e_{s}=6.11 \exp (19.7 t /(t+273))$ is the saturated water vapor pressure. The prediction model of Karasawa, Yamada, and Allnutt [10] has the following form:

$$
\begin{aligned}
\sigma^{2}= & \left(3.420 \times 10^{-3}+1.186 \times 10^{-4} N_{\mathrm{wet}}\right)^{2} G_{C B}\left(D_{e}\right) \\
& \cdot f^{0.9} / \sin ^{2.6} \theta\left(\mathrm{dB}^{2}\right)
\end{aligned}
$$

where $f=$ frequency in gigaherz and $\theta=$ elevation angle. $G_{C B}\left(D_{e}\right)$ is an antenna averaging function described by Crane and Blood [12], dependent on the effective antenna diameter $D_{e}=\sqrt{\eta} D$, where $D=$ antenna diameter and $\eta=$ antenna efficiency. ITU-R [11] presented a similar prediction model, which was derived from Karasawa, Yamada, and Allnutt's model:

$$
\begin{aligned}
\sigma^{2}= & \left(3.6 \times 10^{-3}+1.03 \times 10^{-4} N_{\mathrm{wet}}\right)^{2} G_{H V}\left(D_{e}\right) \\
& \cdot f^{7 / 6} / \sin ^{2.4} \theta\left(\mathrm{dB}^{2}\right)
\end{aligned}
$$


where $G_{H V}\left(D_{e}\right)$ is the Haddon and Vilar antenna averaging function [13]

$$
\begin{aligned}
G_{H V}\left(D_{e}\right)= & 3.8637\left(x^{2}+1\right)^{11 / 12} \sin \left[\frac{11}{6} \arctan \frac{1}{x}\right] \\
& -7.0835 x^{5 / 6}
\end{aligned}
$$

where $x=0.0584 D_{e}^{2} k / L$, where $k$ is the wave number $k=2 \pi / \lambda, \lambda$ is the wavelength and $L$ is the length of the path through the turbulence

$$
L=\frac{2 h}{\sqrt{\sin ^{2} \theta+2 h / R_{e}}+\sin \theta}
$$

where $h$ is the height of the turbulent layer (assumed to be $1000 \mathrm{~m}$ in the ITU-R model and $2000 \mathrm{~m}$ in Karasawa, Yamada, and Allnutt's model) and $R_{e}$ is the effective Earth radius including refraction, which is dependent on station height, and at sea level becomes $8500000 \mathrm{~m}$.

\section{ThE DiURNAL BEHAVIOR OF SCINTILlation VARIANCE COMPaRED WITH METEOROLOGICAL Data}

\section{A. Measurement Setup at Kirkkonummi}

The Radio Laboratory of Helsinki University of Technology participated in the Olympus propagation experiment [14]. The Olympus beacon signals at $19.8 \mathrm{GHz}$, both quasihorizontally and quasi-vertically polarized, and at $29.7 \mathrm{GHz}$, quasi-vertically polarized, were measured at Kirkkonummi, Finland $\left(60.22^{\circ} \mathrm{N}, 24.39^{\circ} \mathrm{E}\right)$. The tilt angle between received polarizations and the local horizon was $-21.5^{\circ}$. All beacon signals were received with one Cassegrain antenna with a diameter of $1.8 \mathrm{~m}$. The antenna efficiency was 0.63 at 19.8 $\mathrm{GHz}$ and 0.38 at $29.7 \mathrm{GHz}$, and the elevation angle toward Olympus was $12.7^{\circ}$. The measurement system included also measurement equipment of temperature, relative humidity, and rain intensity. The rain intensity was measured using a drop counter-type rain gauge. All meteorological measurements were stored with a time resolution of $1 \mathrm{~min}$.

\section{B. Data Analysis}

In this analysis, only the quasi-vertically polarized signal at $19.8 \mathrm{GHz}$ is considered for the period from June 1992 to May 1993. The sampling rate of the beacon signal was 20 $\mathrm{Hz}$. The availability of beacon measurements for the whole year was $89 \%$, and was lowest in spring, when some gaps of several days occurred. The scintillation was separated from the slowly varying signal components by a digital high-pass filter with a cutoff frequency of $0.02 \mathrm{~Hz}$. Next, the 1-min variances were calculated. For the analysis in this paper only the "dry" period was considered, which was detected using the rain intensity measurements. The rain intensity threshold for the rainy or "wet" period was $0.03 \mathrm{~mm} / \mathrm{h}$ using a 10 -min moving average of measured rain intensity integrated over 1 min. The probability of "dry" was $89 \%$.

The distributions of scintillation variance as a function of the hour of the day for different seasons are plotted in Fig. 1. The seasons used here are: Winter $=$ December, January, and
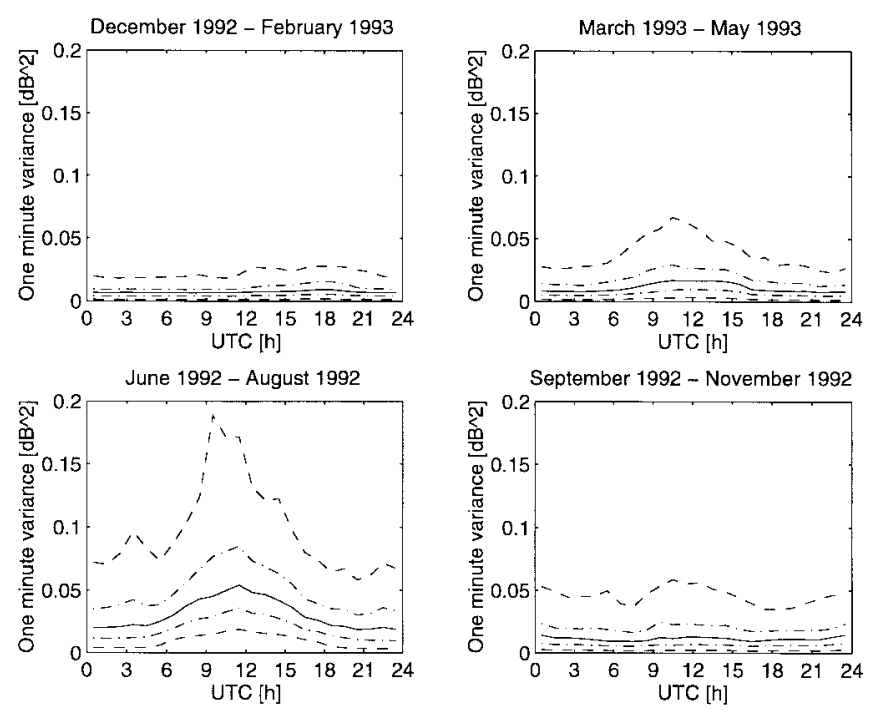

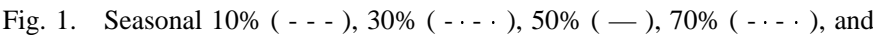
$90 \%$ ( - - ) levels of scintillation variance at $20 \mathrm{GHz}$ as a function of the hours of the day (UTC) for the period June 1992-May 1993.

February; Spring = March, April, and May; Summer = June, July, and August; and Autumn = September, October, and November. The time axis of this figure is in Coordinated Universal Time (UTC). The time difference between local solar time in Kirkkonummi and UTC is 1.626 h, i.e., local solar noon is at $10.374 \mathrm{~h}=10 \mathrm{~h} 22 \mathrm{~m} 26.4 \mathrm{~s}$ UTC.

These results show that the diurnal variability of the scintillation variance is highest in the summer, moderate in the spring and the autumn, and insignificant in the winter. The peak of scintillation variance occurs around local noon. In search for a meteorological parameter which could be correlated to this diurnal behavior of scintillation variance, the average amount, or sky coverage, of Cumulus type clouds was obtained from Warren et al. [15]. Both the mean and the diurnal cycle of the Cumulus cloud amount in Southern Finland are highest in the summer, as shown in Table I. The maximum of the diurnal cycle is at either 13:00 or 14:00 local time. Apparently, this parameter behaves similarly as the scintillation variance.

The diurnal behavior of Cumulonimbus clouds is also similar, but peaks occur later in the afternoon. The $90 \%$ lines of scintillation variances show small afternoon peaks in the summer months, which could correspond to Cumulonimbus clouds. Both Cumulus and Cumulonimbus clouds are lowlevel clouds. The analyzes of the following Sections were performed using data of only Cumulus clouds and of Cumulus and Cumulonimbus clouds together. However, since the inclusion of Cumulonimbus clouds did not make any significant improvement compared to the Cumulus clouds alone, those results are not shown in this paper.

\section{The Cloud-Type Database}

Qualitative analysis above revealed, that the scintillation variance is correlated with Cumulus-type clouds. For a quantitative analysis a better resolution of cloud information is needed. Such cloud-type information is obtainable from the NDP026B database, which is a common database of CDIAC 
TABLE I

Diurnal Variation of Cloud Amounts for Different Seasons in Southern Finland (60-65 N, 20-30 E) [15]

\begin{tabular}{llccc}
\hline Cloud type & Season & Mean (\%) & Amplitude (\%) & Maximum (h, local time) \\
\hline Cumulus & Winter & $\mathbf{0}$ & 0.2 & 13 \\
& Spring & 2 & 3.0 & 14 \\
& Summer & 5 & 6.5 & 13 \\
& Autumn & 2 & 2.1 & 13 \\
\hline Cumulonimbus & Winter & 1 & 0.2 & 13 \\
& Spring & 2 & 2.1 & 15 \\
& Summer & 7 & 5.0 & 16 \\
& Autumn & 3 & 1.6 & 14 \\
\hline
\end{tabular}

and NCAR [16]. This database consists of edited synoptic cloud reports from ships and land stations around the globe from December 1981 to November 1991. The time resolution of this database is 3 or $6 \mathrm{~h}$, i.e., observations are performed at 0:00, 3:00, 6:00, 9:00, 12:00, 15:00, 18:00, and 21:00 UTC or $0: 00,6: 00,12: 00$, and 18:00 UTC.

The data set contains 124 million reports from land stations and 15 million reports from ships. Each report is 56 characters in length. The archive ${ }^{1}$ consists of 240 files, one file for each month of data, and with land and ocean data in separate files.

In this study, besides the time and space information, only the following synoptic codes were used: the "low cloud type" gives the classification of low-level clouds and the "lower cloud amount" gives the amount of sky covered with low-level clouds. This is because only low-level clouds are associated with microwave signal scintillation. The low cloud amount can have integer values from 0 to 8 indicating how many eighth parts of the sky are covered with low-level clouds.

\section{Quantitative Correlation Analysis in Kirkkonummi}

The 1-min variances and the wet part of refractivity, calculated from the temperature and humidity measurements at the same site, were averaged over 3-h periods for each season. The seasonal and diurnal variations of the scintillation variance and the wet part of refractivity are shown in Fig. 2. This figure also shows the variations of the average Cumulus-type cloud amount. From the CDIAC database the time series (3-h time resolution) of Cumulus (Cu)-type cloud amounts were calculated using data from all land stations within an area of $2.5^{\circ} \times 2.5^{\circ}$ around the measurement site. For each month and each observation time, the averages over a decade were calculated. Arbitrary units have been used in this figure to put these three totally different units in the same graphs. The scales of these arbitrary units remain the same for all seasons. The correlation coefficients between variance and meteorological parameters are given in Table II. The correlation of the whole year was calculated using all data points, i.e., four seasons $x$ eight diurnal periods.

The seasonal scintillation variance is clearly correlated with $N_{\text {wet }}$, but the diurnal cycle of $\sigma^{2}$ cannot be predicted from the variation of $N_{\mathrm{wet}}$. The correlation between $\sigma^{2}$ and the Cumulus cloud amount is much better than the correlation between $\sigma^{2}$ and $N_{\text {wet, }}$, except in the winter when hardly any diurnal variation was found for these parameters.

\footnotetext{
${ }^{1}$ ftp.cdiac.esd.ornl.gov/pub/ndb026b
}
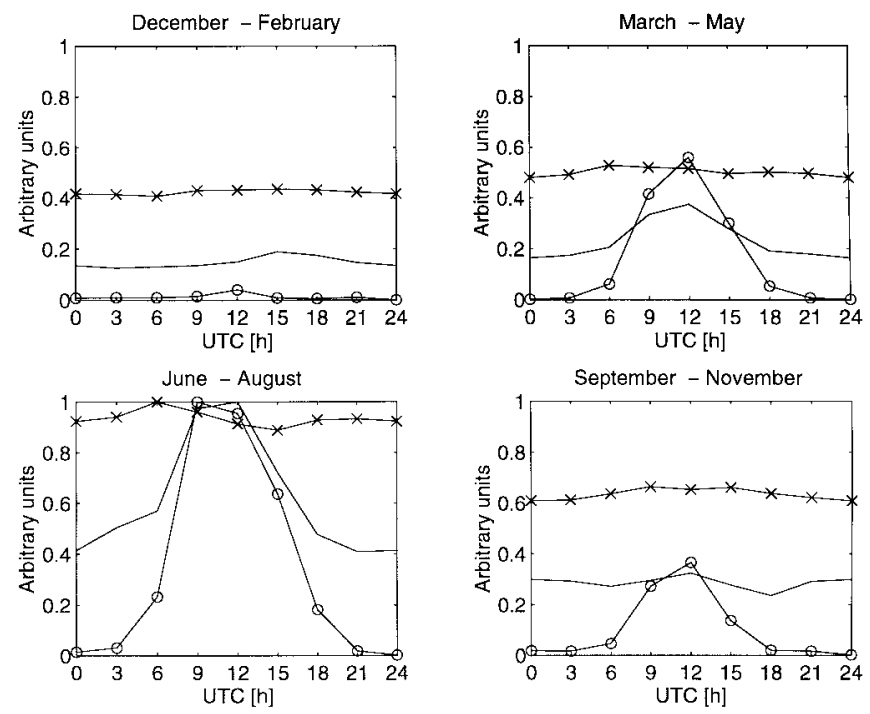

Fig. 2. The diurnal and seasonal variation of the scintillation variance $(-)$, wet part of the ground refractivity ( $-\mathrm{x}-)$, and average Cumulus cloud amount ( - - - ).

TABLE II

Correlation CoEfFicients BetweEn Scintillation Variance $\sigma^{2}$ and Meteorological Data $\left(N_{\text {wet }}, C u\right)$

\begin{tabular}{lrr}
\hline Period & $N_{\text {wet }}$ & \multicolumn{1}{c}{$C u$} \\
\hline Winter & 0.78 & $-\mathbf{0 . 0 8}$ \\
Spring & 0.54 & 1.00 \\
Summer & $-\mathbf{0 . 0 8}$ & 0.98 \\
Autumn & $-\mathbf{0 . 0 1}$ & $\mathbf{0 . 5 7}$ \\
\hline Whole year & $\mathbf{0 . 8 3}$ & $\mathbf{0 . 8 5}$ \\
\hline
\end{tabular}

\section{New Meteorological Prediction Method of the DIURNAL BEHAVIOR OF THE SCINTILLATION VARIANCE}

\section{A. Scintillation Measurements Used in the Modeling}

In Section III it was shown that the measured diurnal variation of scintillation in Kirkkonummi cannot be predicted using only the refractivity $N_{\text {wet }}$. The goal of our study is to develop a global model, therefore, in this chapter the model comparisons are calculated using as many measurements as possible. The description of the various sites is given below and the site parameters relevant for data analysis are summarized in Table III.

In Austin, TX [7], the University of Texas has been involved in observing INTELSAT satellite beacons for over four years. The data reported pertain to the period from June 
TABLE III

The Site Parameters of the Measurements Used for the Modeling of Diurnal Behavior of Scintillation with Meteorology

\begin{tabular}{llccccl}
\hline Ground station & coordinates $\left(^{\circ}\right)$ & $f(\mathrm{GHz})$ & $\theta\left(^{\circ}\right)$ & $D(\mathrm{~m})$ & $\eta$ & Period \\
\hline Austin [7] & $\mathbf{3 0 . 3 9} \mathrm{N}, \mathbf{2 6 2 . 2 7} \mathrm{E}$ & 11.2 & 5.8 & 2.4 & & $\mathbf{6 / 8 8 - 5 / 9 2}$ \\
Goonhilly [6] & $\mathbf{5 0 . 0 5} \mathrm{N}, 354.27 \mathrm{E}$ & 11.2 & 3.27 & 1.44 & 0.7 & $1 / 89-12 / 89$ \\
Kirkkonummi & $60.22 \mathrm{~N}, 24.39 \mathrm{E}$ & 19.77 & 12.7 & 1.8 & $\mathbf{0 . 6 3}$ & $6 / 92-5 / 93$ \\
Yamaguchi [5] & $\mathbf{3 4 . 1 8} \mathrm{N}, 131.55 \mathrm{E}$ & 11.45 & 6.5 & 7.6 & & $1 / 83-12 / 83$ \\
\hline
\end{tabular}

TABLE IV

Accuracy of the Diurnal and Seasonal Scintillation Intensity Prediction Model of Karasawa et al. and the New Method

\begin{tabular}{lccc}
\hline Models & correlation & mean relative error, \% & rms relative error, \% \\
\hline Model of Karasawa & 0.866 & 25.56 & 41.83 \\
New method using $N_{\text {wet }}$ and $P(C u)$, equation (7) & 0.918 & -2.31 & 15.21 \\
\hline
\end{tabular}

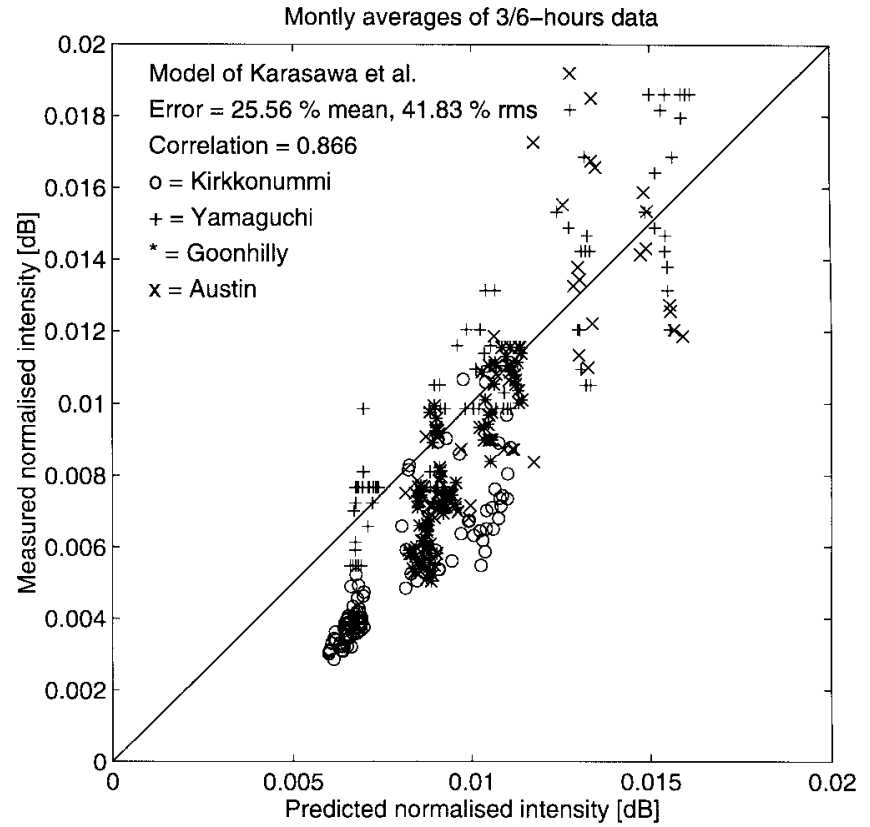

Fig. 3. Measured versus predicted diurnal and seasonal scintillation intensity (standard deviation) using the model of Karasawa et al. and data from all four sites.

1988 to May 1992, during which the right-hand circularly polarized $11.2 \mathrm{GHz}$ signal from a succession of three geostationary satellites was monitored. The receiver output was sampled at $2 \mathrm{~Hz}$. Using filtering and a 110-K radiometric sky temperature threshold, the "dry" scintillation data set was separated. Slowly varying signal components were removed by subtracting the 3-min moving average value. A contour plot of the hourly average standard deviation of the beacon level versus the hour and the month is given for the whole four-year measurement period.

In Goonhilly, U.K. [6], British Telecom carried out an experiment under contract to the INTELSAT organization to gather low-elevation data of tropospheric scintillation. The database, which was analyzed at Bradford University, contained continuous 10-min standard deviations of signal strength at $11.2 \mathrm{GHz}$ measured at sampling rate of $2 \mathrm{~Hz}$ between November 1987 and October 1990. A contour plot of the mean standard deviation as a function of the month and the hour was shown for the year 1989.

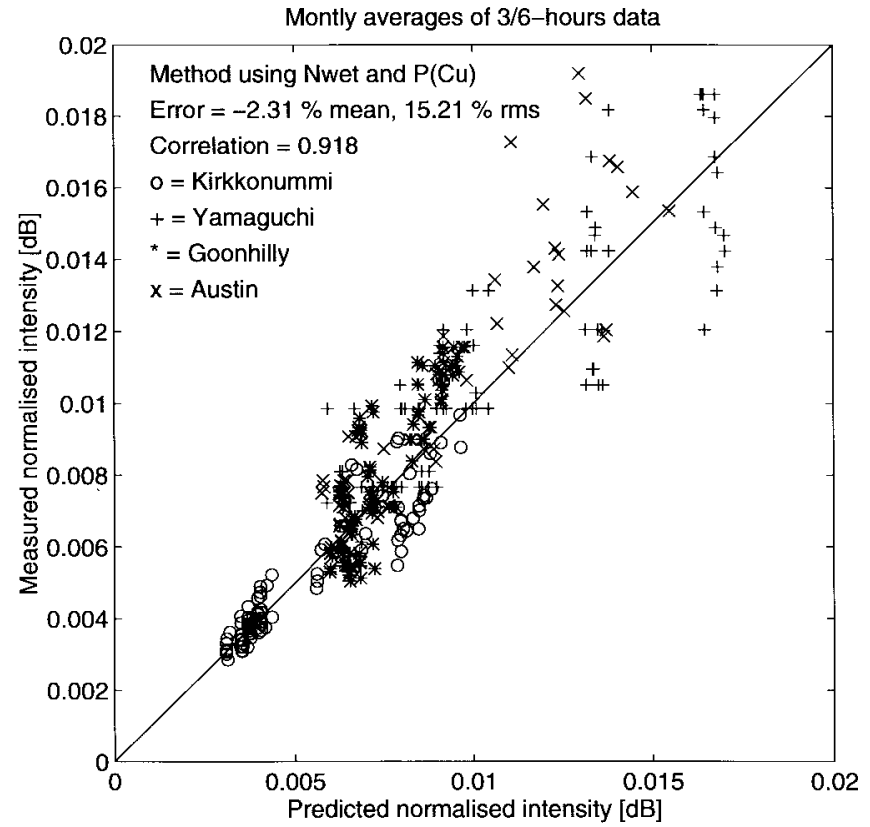

Fig. 4. Measured versus predicted diurnal and seasonal scintillation intensity (standard deviation) using $N_{\text {wet }}$ and the probability of Cumulus clouds (7) and data from all four sites.

In Kirkkonummi, the data were analyzed as described in the previous section.

In Yamaguchi, Japan [5], long-term propagation experiments have been carried out using the INTELSAT-V satellite link during the year 1983. The $11.45-\mathrm{GHz}$ beacon data were sampled at $1 \mathrm{~Hz}$, and the scintillation was separated by subtracting the 5-min moving averages from the data. The standard deviations due to scintillation were calculated over every hour. The data for the corresponding hours of the day averaged over each month was given in a figure using a color coding.

\section{B. Data Analysis}

From the measurements at Austin, Goonhilly, and Yamaguchi, the monthly mean standard deviation values of 3-h (6 $\mathrm{h}$ in Austin) periods centered at 0:00, 3:00, 6:00, 9:00, 12:00, 15:00, 18:00, and 21:00 UTC were extracted from large paper copies by hand. The bins of these graphs were $0.1 \mathrm{~dB}$, resulting in an accuracy of about $0.05 \mathrm{~dB}$, i.e., 5-25\%. For a comparison 

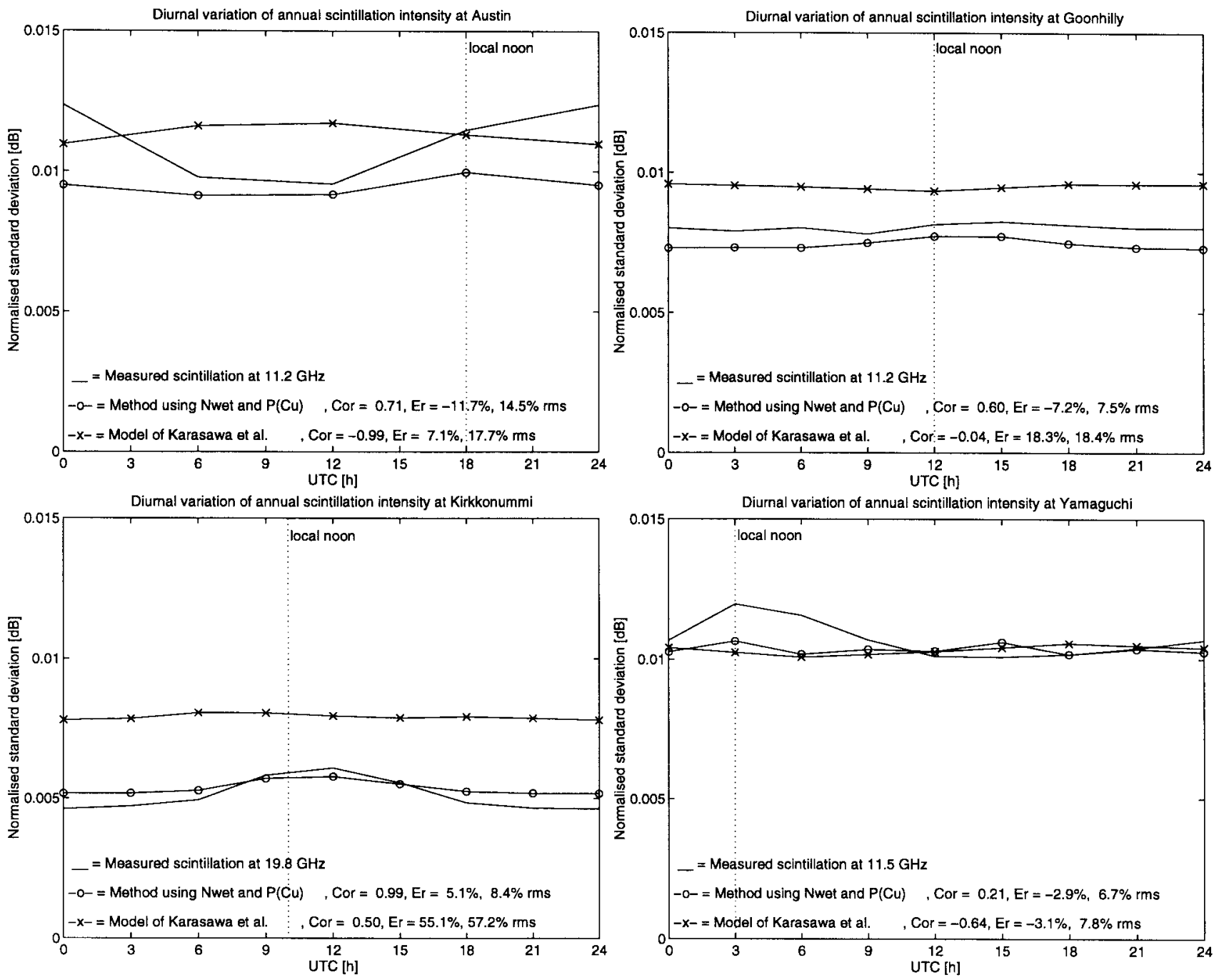

Fig. 5. Measured and predicted diurnal behavior of annual scintillation intensity (standard deviation) for different sites: Austin upper left, Goonhilly upper right, Kirkkonummi lower left, and Yamaguchi lower right.

of the results of different links with different link parameters, some normalization is needed. The normalization used here is done using the frequency and elevation scaling according to Karasawa, Yamada, and Allnutt [10] and the antenna averaging function of Haddon and Vilar [13] (assuming $h=2000 \mathrm{~m}$ ), so the normalized scintillation standard deviation or intensity is expressed as

$$
\sigma_{\text {norm }}=\frac{\sigma}{\sqrt{G_{H V}\left(D_{e}\right)} f^{0.45} / \sin ^{1.3} \theta} .
$$

A value of 0.75 is assumed for the antenna efficiency, if it is missing in Table III, because the value is not given in the corresponding reference.

For the meteorological information a large extensive meteorological database has been purchased for our use, under ESA contract, from the European Center for Medium-range Weather Forecasts (ECMWF). The database contains height profiles of pressure, temperature and absolute humidity on 23 height levels, for grid points over the whole Earth with resolution of $1.5^{\circ}$ both in longitude and latitude, and for every $6 \mathrm{~h}(0: 00,6: 00,12: 00$, and 18:00 UTC) in the period from October 1992 to September 1994. It has been obtained by a combination of various measurements and model-based predictions. This database was used for the calculation of the wet part of refractivity $N_{\text {wet }}$ at 0:00, 6:00, 12:00, and 18:00 UTC for Austin, Goonhilly, and Yamaguchi, using spatially linearly interpolation between the four nearest grid points. The results were averaged over each month. For Goonhilly and Yamaguchi, the monthly averages at 3:00, 9:00, 15:00, and 21:00 were linearly interpolated. The resulting $N_{\text {wet }}$ data were used as a meteorological input for the scintillation prediction models. A comparison between the measured scintillation standard deviations at Kirkkonummi and the other three sites, and the prediction using the model of Karasawa et al. is shown in Fig. 3. The evaluation of the prediction accuracy is included in the figure and shown in Table IV. The accuracy is calculated using a relative error, using all 336 data points from all sites together.

\section{Proposed Prediction Model}

A new prediction model will be derived using the cloud information extracted from the CDIAC database. From this database, the time series (3- or 6-h time resolution) of $\mathrm{Cu}$ - 
mulus $(C u)$-type cloud amounts, introduced in Section III, were calculated using the data from all land stations within areas of $2.5^{\circ} \times 2.5^{\circ}$ around the points of interest. For each month and each observation time, the averages over a decade were calculated. Since no information is available concerning which part of the sky is cloud-covered, the cloud amount $C u$ represents the probability $P(C u)$ of a cloud to appear in the satellite link, so the new model can be considered a probabilistic one. The scintillation variance is assumed to be a superposition of the dependence on the wet part of refractivity and the dependence on the probability of Cumulus clouds.

A least-mean-square error fit was performed using these assumptions and all the measured data. The equation describing the meteorological dependence of the scintillation standard deviation as a function $N_{\text {wet }}$ and the probability of Cumulus clouds $P(C u)(\%)$ becomes

$$
\begin{aligned}
\sigma_{\text {norm }}= & 1.34 \times 10^{-4} \overline{N_{\text {wet }}}+7.74 \times 10^{-5}+9.13 \\
& \times 10^{-5} P(\mathrm{Cu})(\mathrm{dB})
\end{aligned}
$$

where the overscore denotes the average over the diurnal cycle. The measured scintillation standard deviations are compared to the predicted values using this method in Fig. 4. The evaluation of the prediction accuracy of this model is included in Table IV. This result shows a significant improvement of the diurnal and seasonal correlation and prediction accuracy, when cloud information is included in the prediction model.

To study only the diurnal effect, the diurnal behavior of the annual tropospheric scintillation intensity for all four measurement sites is shown in Fig. 5. In all sites significant improvement of the correlation coefficient is found when the new method is used. The highest correlation coefficients of the new method are found in Kirkkonummi and in Austin where also the improvement of the correlation is highest. The correlation coefficients are lower in Goonhilly and in Yamaguchi, but on the other hand, the rms errors are lowest at those sites.

\section{CONCLUSION}

The diurnal variations of the wet part of refractivity have been found to be very small. Because the current scintillation prediction models use the wet part of refractivity as the only meteorological input parameter, these models cannot predict the measured diurnal variation of the scintillation variance. The use of a new method including cloud information, introduced in Section IV, significantly improves the prediction accuracy of the diurnal behavior of the scintillation variance, compared to the current models. However, this method is based on data from only four sites because of scarcity of experimental data. For the world-wide validation or modification of the model, it is necessary that more data become available of the diurnal variation of scintillation, measured in different climatic regions of the world. When such data will be available, one should recheck whether the inclusion of also the Cumulonimbus clouds would be an improvement or not.

\section{ACKNOWLEDGMENT}

Any views expressed in this paper do not necessarily represent those of ESA. The authors like to thank J. P.
V. Poiares Baptista (ESTEC) for his useful comments and technical support.

\section{REFERENCES}

[1] A. Vander Vorst, D. Vanhoenacker, and L. Mercier, "Fluctuations on OTS-earth copolar link against diurnal and seasonal variations," Electron. Lett., vol. 18, pp. 915-917, Oct. 1982.

[2] C. N. Wang, F. S. Chen, C. H. Liu, and D. J. Fang, "Tropospheric amplitude scintillations at C-band along satellite up-link," Electron. Lett., vol. 20, pp. 90-91, Jan. 1984.

[3] G. Ortgies and F. Rücker, "Diurnal and seasonal variations of OTS amplitude scintillations," Electron. Lett., vol. 21, pp. 143-145, Feb. 1985.

[4] O. P. Banjo and E. Vilar, "Measurement and modeling of amplitude scintillations on low-elevation Earth-space paths and impact on communication systems," IEEE Trans. Commun., vol. COM-34, pp. 774-780, Aug. 1986.

[5] Y. Karasawa, K. Yasukawa, and M. Yamada, "Tropospheric scintillation in the 14/11 GHz bands on Earth-space paths with low elevation angles," IEEE Trans. Antennas Propagat., vol. 36, pp. 563-569, Apr. 1988.

[6] E. C. Johnston, D. L. Bryant, D. Maiti, and J. E. Allnutt, "Results of low elevation angle $11 \mathrm{GHz}$ satellite beacon measurements at Goonhilly," in IEE Int. Conf. Antennas Propagat. Publ. 333, Apr. 1991, vol. 1, pp. 366-369.

[7] W. J. Vogel, G. W. Torrence, and J. E. Allnutt, "Scintillation fading on low elevation angle satellite path: Assessing the Austin experiment at 11.2 GHz," in IEE Int. Conf. Antennas Propagat. Publ. 370, Mar./Apr. 1993, vol. 1, pp. 48-51.

[8] I. E. Otung, M. S. Mahmoud, and J. R. Norbury, "Radiowave amplitude scintillation intensity: Olympus satellite measurements and empirical model," Electron. Lett., vol. 31, pp. 1873-1875, Oct. 1995.

[9] E. Salonen, S. Karhu, and J. Tervonen, "Prediction of total atmospheric attenuation for low fade-margin satellite communications," in 7th URSI Commission F. Open Symp. "Wave Propagation and Remote Sensing," Ahmedabad, India, Nov. 1995, pp. 209-212.

[10] Y. Karasawa, M. Yamada, and J. E. Allnutt, "A new prediction method for tropospheric scintillation on Earth-Space paths," IEEE Trans. Antennas Propagat., vol. 36, pp. 1608-1614, Nov. 1988.

[11] ITU-R, "Effects of tropospheric refraction on radio-wave propagation," Recommendations and Reports of the ITU-R, Düsseldorf, Annex to vol. 5, Rep. 718-3, pp. 149-188, 1990.

[12] R. K. Crane and D. W. Blood, Handbook for the Estimation of Microwave Propagation Effects, NASA Contract NASS-25341, NASA GSFC Greenbelt, MA, Tech. Rep. 1, Doc. 7376-TRI, June 1979.

[13] J. Haddon and E. Vilar, "Scattering induced microwave scintillations from clear air and rain on Earth space paths and the influence of antenna aperture," IEEE Trans. Antennas Propagat., vol. 34, pp. 646-657, May 1986.

[14] J. P. V. Poiares Baptista and P. G. Davies, Eds., Reference Book on Attenuation Measurement and Prediction. Noordwijk, The Netherlands, Nov. 1994, ESA Publ. WPP-083, vol. 1, ESA/ESTEC.

[15] S. G. Warren, C. J. Hahn, J. London, R. M. Chervin, and R. L. Jenne, "Global distribution of total cloud cover and cloud type amounts over land," Boulder, CO, NCAR Tech. Note TN-273+STR, Oct. 1986.

[16] C. J. Hahn, S. G. Warren, and J. London, "Edited synoptic cloud reports from ships and land stations over the globe, 1982-1991," NDP026B, Carbon Dioxide Information Analysis Center, Oak Ridge National Laboratory, Oak Ridge, TN, 1996; also available from Data Support Section, National Center for Atmospheric Research, Boulder, CO.

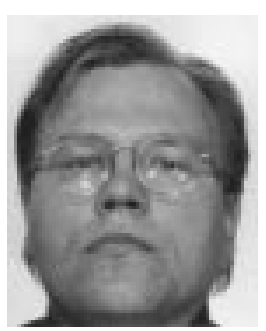

Jouni K. Tervonen was born in Turku, Finland, in 1965. He received the Dipl.Eng. (M.S.), Lic. Tech., and D.Tech. degrees in 1992, 1995, 1997, respectively, all in electrical engineering, from the Helsinki University of Technology, Espoo, Finland

Since 1992, he has been a Research Engineer with the Radio Laboratory of the Helsinki University of Technology. His main research interest is the modeling of atmospheric effects of radio wave propagation for satellite communications. 
Max M. J. L. van de Kamp was born in Driebergen, The Netherlands, in 1963. He received the M.Sc. degree in telecommunications from Eindhoven University of Technology (EUT), The Netherlands, in 1989.

He has been a Research Assistant in different research projects for the European Space Agency (ESA) at EUT from 1990 to 1994, at Helsinki University of Technology, Finland, from 1995 to 1997, and since 1997 again at EUT. His main activities in these projects have been in satellite wave propagation research in the Olympus Propagation Experiment (OPEX).

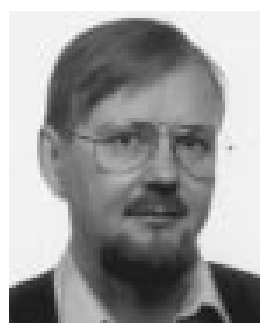

Erkki T. Salonen received the Dipl.Eng. (M.S.), Lic.Tech, and D.Tech. degrees in electrical engineering from the Helsinki University of Technology, Espoo, Finland.

Since 1997, he has been at the Telecommunication Laboratory of the University of Oulu, where he was nominated in a new professorship of radio engineering. Earlier he was in charge of the radio wave propagation studies at the Radio Laboratory of the Helsinki University of Technology. His main research interest is modeling of atmospheric attenuation phenomena for satellite communication. 